\title{
Eastern Mediterranean health
}

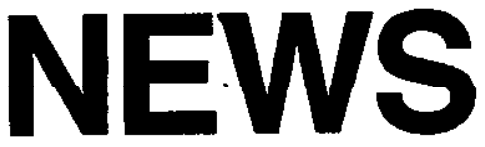

Annual meeting of Reglonal Directors of WHO and UNICEF

MTs Sarojini Vittachi, UNICEF Regional Director for the Middle East and North Africa, and Dr Hussein A. Gezairy, World Health Organization Regional Director for the Eastern Mediterranean, held their annual meeting at the Regional Office for the Eastern Mediterranean in Alexandria, Egypt, on 28 and 29 June 1995. The meeting was attended by senior officials from both organizations.

In his opening remarks, Dr Gezairy reiterated that collaboration between the two agencies had started with the Expanded Programme on Immunization; now there is a wide range of joint programmes with Member countries. He gave examples of close collaboration in poliomyelitis eradication, vaccine production, oral rehydration, neonatal tetanus elimination, promotion of breastfeeding, use of iodized salt, and many other fields of cooperation. Dr Gezairy highlighted other areas of collaboration that deserve sustained attention by the two parties in collaboration with the governments concerned, such as the basic minimum needs programme, the action-oriented school health programme, and the Healthy Cities and Healthy Villages concepts. The Regional Director welcomed the UNICEF team and looked forward to a fruitful indepth dialogue during this session. Mrs Vittachi announced the successful achievement of the mid-decade goals set by the World Summit for Children in 1990, thanks to the close collaboration with WHO, Member States and the League of Arab States.

Mrs Vittachi referred with great pride to the relentless efforts made by Dr James Grant, the late Director-General of UNICEF, who left his fingerprints on UNICEF's development and progress over the past 15 years. She then spoke of the successes achieved, such as immunization days, baby-friendly hospitals and the reduction in infant mortality rates. She added that there is a need to build up the capacity required to maintain these achievements at country level.

Over the two days, WHO and UNICEF staff members reviewed the present situation, the progress made, and future prospects of their mutual collaboration in the multiple programme areas in which they are involved.

\section{Task force on Healthy Clties}

WHO's Regional Office for the Eastern Mediterranean (WHO/EMRO) initiated the Healthy Cities programme in the Eastem Mediterranean Region (EMR) in 1988. Since then, the programme has expanded rapidly in many countries of the Region. In the light of their needs, the Member States have urged WHO/EMRO to further expand this programme and provide the required human and material resources. With this in mind, World Health Organization headquarters and WHO/EMRO have devised a joint work plan to support the countries of the EMR. This plan is part of an Interre-

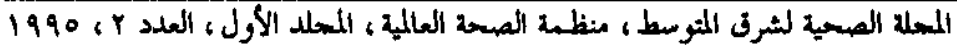


gional Programme on Healthy Cities designed to address the major orlentations of the WHO Ninth General Programme of Work, while forming an important component of the WHO Global Policy Strategy for Health and Environment, which was endorsed by the World Health Assembly in 1993.

In the meantime, and in view of the interest the programme has generated and the importance it has acquired, "healthy cities" has been selected as the theme for World Health Day 1996. Therefore, and with a view to providing effective integrated technical support, Dr Hussein A. Gezairy, WHO Regional Director for the Eastern Mediterranean, has decided to establish a task force on Healthy Cities, whose terms of reference are as follows:

- to ensure proper coordination of different WHO programmes in urban settings.

- to share information, and help in identifying potential resources under different national programmes to address urban health and envirnnment issues.

- to review the promotional and technical documents produced by the Healthy Cities programme, and assist in the development of integrated health approaches in the cities of the EMR.

- to act as a technical advisory group on the concept, analysis and development of Healthy Cities projects, activities, initiative, etc.

- to advise on resource mobilization and securing support from funding and donor agencies for Healthy Cities activities.

- to advise on promotion of Healthy Cities concepts and activities, especially in the media.
Training course on strengthening of leakage detection/reduction programmes in countries of WHO Eastern Mediterranean Reglon, Alexandrla, 4-8 June 1995

The WHO Regional Office for the Eastern Mediterranean, in collaboration with the Islamic Development Bank, organized this training course in Alexandria from 4 to 8 June 1995.

The objectives of the course were to familiarize the participants with the techniques and managerial methodologies of water leakage detection and control, to emphasize the health and economic consequences of water leakage, to share experiences, and assist the participants developing programmes for leakage detection and control. Trainees from 14 Eastern Mediterranean countries participated in this training course.

\section{Fifth and special meeting of the technlcal advisory committee (decade of CEHA exlstence), CEHA, Amman, 28-30 May 1995}

The World Health Organization Regional Centre for Environmental Health Activities (CEHA) convened the above meeting at CEHA headquarters in Amman from 28 to 30 May 1995.

The first objective of the meeting was to evaluate the achievements of CEHA in implementing the 1994-1995 workplan and the recommendations endorsed by the Technical Advisory Committee (TAC) at its fourth meeting in 1993. The second objective was to review the proposed CEHA workplan for the coming biennium 1996-1997, and make further recommendations for CEHA's future directions, which can be used as guidelines on long-term goals, technical aspects and improvement of operational efficiency and effectiveness. 
Member countries of the Region are invited to serve on the TAC in rotation, while maintaining certain overlapping and continuity. For the fifth meeting, the committee is constituted of four members from Egypt, Jordan, Kuwait and Pakistan, in addition to two coopted members from Morocco and the Syrian Arab Republic. Professot M. Scheafer and Mr Odyer Sperandio have also been invited to attend as WHO Temporary Advisers.

\section{The Reglonal Consultatlve Committee holds Its nIneteenth meeting in EMRO, Alexandria}

Members of the Eastern Mediterranean Regional Consultative Committee (RCC), who are designated in their personal capacity, meet twice annually to review the WHO's programme in the Region and to advise the Regional Director on any other topics referred to them by him.

The membership of the RCC is as follows:

- Dr A R. Al Awadi, Execntive Secretary, Regional Organization for the Protection of the Marine Environment (ROPME), Kuwait

- Dr A. Al-Majali, Senator, Jordan

- Mr A. Al Badi, Minister of Health, the United Arab Emirates

- Mr M.R. Bencheikh, Member of Parliament, Morocco

- Professor I. Beit-El-Mal, Assistant Professor of Paediatrics, Faculty of Medicine, Al-Arab Medical University, Libyan Arab Jamahiriya

- Professor M.E. Chatty, Minister of Health, Syrian Arab Republic

- Dr I. Fazel, President of the Academy of Medical Sciences, Islamic Republic of Iran
- Professor M. Gabr, Secretary-General, Egyptian Red Crescent Society, Cairo, Egypt

- Mr M. Hamada, Minister of Public Health, Lebanon

- Dr S. Mahmood, former Senior Chief, Health Planning, Islamabad, Pakistan.

The Committee held its nineteenth meeting on 25 and 26 May 1995, in the Regional Office for the Eastern Mediterranean, Alexandria, Egypt, to consider the following issues:

- adolescent girls-the women and mothers of tomorrow

- the concept of quality assurance and its application in primary health care services

- health legislation

- cancer prevention and control

- health policy and planning.

\section{The United Arab Emirates Health Foundation Prize, 19951}

This prize, established on the initiative of and with funds provided by the government of the United Arab Emirates, is awarded to a person or persons, institution or institutions, or a nongovernmental organization or organizations, who have made an outstanding contribution to health development. The 1995 prize was awarded jointly to the Child Survival Project of Egypt, and to Dr AbdulRahman Abdul-Aziz Al-Swailem of Saudi Arabia.

The Child Survival Project of Egypt is the culmination of efforts in the field of child survival and safe motherhood in Egypt. The overall goal is to reduce mortality and morbidity among children under five years of

'Press Release WHA/7. WHO, Geneva, 1995

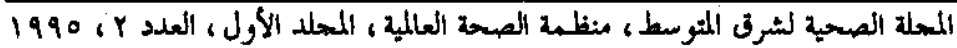


age, and women of child-bearing age. It initiated its activities in 1984, with the implementation of the accelerated programme of immunization. It was formally organized in 1988, and became fully operational in 1990 . It is supervised by the Ministry of Health and comprises three technical components-immunization, control of acute respiratory infections, and child spacing and matemal and child health care programme.

In its six years of operation between 1989 and 1994, the Project has had a tremendous impact on the reduction of infant and child mortality through vaccination against childhood diseases and neonatal tetanus. It has improved the performance of primary health care systems in the areas of maternal and child health, immunization and the control of acute respiratory infections, introduced a national hepatitis B control and elimination programme, eliminated neonatal tetanus, and is approaching the goal of poliomyelitis eradication. It bas developed a national neonatal care system, and promoted initiative for safe motherbood and the reduction of mortality rates among mothers.

\section{Dr Abdul-Rahman Abdul-Aziz Al-} Swailem was born in 1938. Dr Al-Swailem graduated from Munich University with an MBBS in 1966 and continued his studies at Cairo University. He is a fellow of the Royal College of Physicians in the United Kingdom. He started his career in 1977 as head of the Paediatric Department at the Maternity and Children's Hospital in Riyadh and occupied this post until 1982. when he became Director-General of Health Affairs, Eastern Province, Saudi Arabia. From 1983 until 1988 he was Assistant Deputy Minister for Curative Medicine, Ministry of Health, Saudi Arabia, and since 1988 has been Deputy Minister for Executive Affairs.

Dr Al-Swailem has played a crucial role in the formulation of national policy and strategy for health for all, which were implemented under his general supervision. As a result, the quality of health care in the country has improved, and there has been a notable reduction in maternal and infant mortality in addition to an overall reduction of morbidity and mortality. Under his direction, a vaccination programme against all vaccine-preventable diseases has been successfully implemented, covering more than $90 \%$ of children under one year of age.

He has initiated many research projects in the fields of maternal and child health and renal disease and has supervised the Saudi Centre for Organ Transplantation since its inception.

Dr Al-Swailem has performed outstanding work in health development in Saudi Arabia and has brought primary health care to standards comparable to the best provided elsewhere. His numerous achievements in the health field transcend national boundaries and benefit the whole region.

\section{The Dr A.T. Shousha Foundation Prize}

This prize is awarded to persons who have made a significant contribution to improvement of the health situation in the Eastern Mediterranean Region of WHO. The Dr A.T. Shousha Foundation Prize for 1995 was awarded to Dr Ibrahim Mohammed Yacoub from Bahrain. Bom in 1935, Dr Yacoub graduated from the American University of Beint in 1954 (BSc in medicine) and continued his studies at the American University of Beirut School of Medicine, and the University of Medicine in New York in (MD in paediatrics, 1959). In 1970 he became Director-General of Curative Medicine at the Ministry of Health in Bahrain. From 1975 until 1992 be was Assistant Undersecretary for Primary Care and Public Health in the Ministry of Health, and he is at present Assistant Undersecretary and Act- 
ing Undersecretary for Primary and Public Health.

Dr Yacoub has been Assistant to the Secretary-General of the Secretariat of Gulf States since its formation in 1976. During his career in government he has actively promoted primary heal th care policies in his country. He was instrumental in developing the College of Health Sciences, and participated in the establishment of the Gulf Medical School in Bahrain. He is a member of renowned international associations such as the Arab Medical Association, the Family Planning Association and the Bahrain Gulf Medical Association. He is also a founder member of the Bahrain Medical Society and a member of the American Academy of Pediatrics.

\section{Twelve new members for WHO Executive Board'}

The Forty-eighth World Health Assembly elected the following 12 Member States (listed in alphabetical order) to designate a person to serve on the Executive Board of the World Health Organization:

$\begin{array}{lll}\text { Algeria } & \text { Argentina } & \text { Australia } \\ \text { Bahrain } & \text { Barbados } & \text { Bhutan } \\ \text { Brazil } & \text { Croatia } & \text { Egypt } \\ \text { Ireland } & \text { Republic of Korea } & \text { Zimbabwe }\end{array}$

They replace the following countries, whose terms of office came to an end at the closure of the Forty-eighth World Health Assembly on 12 May 1995 :

$\begin{array}{lll}\text { Cameroon } & \text { Canada } & \text { Jamaica } \\ \text { Japan } & \text { Mexico } & \text { Mongolia } \\ \text { Portugal } & \text { Qatar } & \text { Swaziland } \\ \text { Syrian Arab Republic } & \text { United Kingdom }\end{array}$

The persons designated take their seats on the Board immediately after the closure of the Forty-eighth World Health Assembly.

The Eastem Mediterranean Region is thereby represented in the Executive Board by Bahrain, Egypt, Kuwait, Morocco and Pakistan.

The Executive Board consists of 32 members who are highly qualified in the field of health, and designated by Member States chosen by the World Health Assembly on the basis of equitable geographical distribution. The main functions of the Executive Board are to give effect to the decisions and policies of the Health Assembly, to advise it and to facilitate its work. Among other functions, the Executive Board is responsible for preparing the agenda of the Health Assembly and for taking emergency measures within the functions and financial resources of the Health Assembly. In particular, it may authorize the Director-General to take the necessary steps to combat epidemics, to participate in the organization of health relief to victims of a disaster and to undertake studies and research, the urgency of which is brought to the attention of the Board by any member or by the DirectorGeneral.

\section{Collaboration with the London School of Hyglene and Troplcal Medicine}

The London School of Hygiene and Tropical Medicine intends to produce a historical dictionary of the World Health Organization. The WHO Regional Office for the Eastern Mediterranean has welcomed this initiative, which is very timely, as it coincides with the forthcoming 50th Anniversary of WHO in 1998.

\footnotetext{
${ }^{1}$ Press Relesse WHA12. WHO, Geneva, 12 May 1995.
} 
Dracuncullasls eradicatlon: the international commission for certfication is established'

Dr Hiroshi Nakajima, Director-General of the World Health Organization, announced the establishment of an International Commission for the Certification of Dracunculiasis Eradication (ICCDE). The role of this independent commission, following the model of certification of smallpox eradication, is to advise the unit of Dracunculiasis Eradication in the Division of Control of Tropical Diseases on the validity of the information of former endemic countries claiming that cases of indigenous dracunculiasis no longer exist.

After consultation with WHO Regional Offices, UN Agencies, Global 2000 Carter Presidential Centre, and several international organizations, the following list of members was approved by the DirectorGeneral:

- Dr Abdul Rahman Al-Awadi (Kuwait, Chair)

- Professor Pierre Ambroise-Thomas (France)

- Dr Joel Breman (United States of America)

- Professor Ogobara Dumbo (Mali)

- Dr Pascal Magnussen (Denmark)

- Professor David Molyneux (United Kingdom)

- Dr Aholhassan Nadim (Iran)

- Dr Aluizio Prata (Brazil)

- Dr Bheeshma Kumar Sainanee (India)

- Dr Frederick Wurapa (Ghana)

This commission will meet in Geneva by the end of 1995 and start the process of certification immediately thereafter.

It is interesting to recall that the Chair, Dr Abdul-Rahman Al-Awadi of Kuwait,

${ }^{1}$ Press Release WHA/14. WHO, Geneva, 12 May 1995. was the president of the Thirty-third World Health Assembly, which announced the global eradication of smallpox in May 1980.

\section{The World Health Assembly supports the Palestinlan Authorlty In the fleld of health ${ }^{2}$}

In its most recent meeting in Geneva, the Forty-eighth World Health Assembly affirmed the need to support the efforts of the Palestinian Authority in the field of health to enable it to develop its own health system. It requested Member States, intergovernmental organizations, nongovemmental organizations and regional organizations to provide speedy and generous assistance to help in the achievement of health development for the Palestinian people.

The Assembly requested the DirectorGeneral to continue to provide the necessary technical assistance for supporting health programmes and projects for the Palestinian people during the transitional period. It requested the Director-General to obtain funding from various available sources, to continue efforts to implement the special health assistance programme and to adapt it to the health needs of the Palestinian people.

National Study on the prevalence of vitamin A deflciency in Oman ${ }^{3}$

To determine if vitamin A deficiency (VAD) in Omani children from 6 months to 7 years of age was a matter of public health importance, a joint collaborative national study was undertaken by the Omani Ministry of Health (MOH), WHO, UNICEF, the Programme Against Micronutrient Malnutrition (PAMM) Laboratory at the Centers for Disease Control and Prevention (CDC). Atlanta, Georgia, and Iowa State University at

\footnotetext{
${ }^{2}$ Press Release WHA/16. WHO, Geneva, 13 May 1995. ${ }^{3}$ Community Health and Disease Surveillance Newsletter. January-March 1995, 4(1), Oman, Ministry of Health.
} 
Ames, lowa, during the period from October 1994 to February 1995. The WHO Nutrition Unit, Geneva, provided the technical support; UNICEF provided technical and financial support. The ultimate objective of the investigation was to establish strategies to ensure virtual elimination of VAD, including subclinical forms, among Omani children aged from 6 months to below 7 years by the year 2000 .

Is VAD a public health problem among Omani children under 7 years of age? The data show that:

- VAD is a moderate public health problem among children under 3 years of age.

- The problem is nationwide and not related to sex or relative economic strata as defined for the purposes of this investigation.

- The likely cause of the problem is poor nutrition as a result of lack of information as to what foods are needed to provide a nutritionally adequate diet, particularly for women of reproductive age and young children during the period of complementary feeding and postweaning.

- A series of recommendations are under consideration for ensuring achievement of virtual elimination of VAD in Oman by the year 2000 , such as:

- an intensive advocacy programme among the medical profession and general population

- supplementation of mother's milk immediately after birth and the nutrition of infants and young children together with immunization at 9,15 and 18 months of age

- dietary diversification through education in the field of nutrition

- monitoring the programme by the use of indicators that can be periodically applied to measure progress.
Formation of UNAIDS Theme Group In Sudan

A Theme Group has been established within the UNAIDS system in Sudan. UNAIDS is the newly established joint and cosponsored United Nations AIDS Programme, which will replace the WHO Global Programme on AIDS as of 1 January 1996. The current members of the Theme Group are the WHO Representative to Sudan, as UN Resident Coordinator; UNDP Resident Representative; UNICEF Resident Representative; UNHCR Resident Representative; and UNFPA Country Director. UNESCO and the World Bank are among the cosponsors of UNAIDS but have no representation in Sudan. The Government of Sudan has been invited to participate in the Theme Group in the manner it deems appropriate.

The Theme Group will be the core mechanism for UNAIDS at the country level. However, it is establishing its terms of reference in the light of the local epidemiological situation in Sudan.

\section{The British Broadcasting Corporation transmits an educational programme to Afghanistan}

A memorandum of understanding was concluded on 11 July 1995 between the British Broadcasting Corporation (BBC) on one side, and UNICEF, UNESCO, UNDP, United Nations Women's Organization, the International Committee of the Red Cross and WHO's Regional Office for the Eastern Mediterranean on the other. The parties agreed that the BBC would produce educational radio dramas in the Pashto and Dari languages to be broadcast weekly during a period of 12 months.

In addition to the $\mathrm{BBC}$ broadcasting as outlined above, each of the above-mentioned parties will have the right to exploit

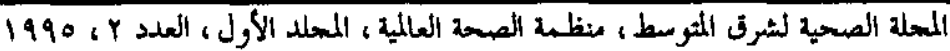


the work in audio form, other than broadcasting, as they deem approprtate.

\section{A regional plan for the prevention and control of emerglng dlseases: Improved survellance and dlagnosis capability for all countrles in the Reglon}

A regional plan for the prevention and control of emerging and resurging infectious diseases has been approved by a regional conference convened by the World Health Organization in Cairo, which completed its deliberations on Wednesday 29 November 1995.

The four-day conference tackled a major public health issue that has acquired increased importance after major outbreak of epidemics such as the plague in India and Ebola haemorrhagic fever in Zaire. Moreover, the new increase in tuberculosis incidence has been a significant cause of worry, as it was on the retreat due to the success of the expanded programme on immunization.

High-level delegations from all Member States in the Region attended the conference, including the managers of the national programmes of immunization, control of communicable diseases and AIDS. Several international agencies also took part. Among these were the Centers for Disease Control and Prevention, Atlanta, USA, and NAMRU.

The regional plan will now be presented to the Regional Committee, WHO's highest governing body at the regional level; in its next session. Once adopted by the Regional Committee, the plan shall be implemented by Member States in collaboration with WHO.

The next issue of the Eastern Mediterranean Health Journal, Vol. 2 No. 1, will be devoted to the subjects discussed at this conference.

\section{Status of papers considered for publication in the Eastern Mediterranean Health Journal as at 31 December 1995}

Papers received 128

Papers published in Vol. 1

Papers accepted, including those published . 63

Papers withdrawn

Papers rejected

Papers under processing

34 